\title{
Correspondence
}

\section{GUILLAIN-BARRE SYNDROME AND IDIOPATHIC THROMBOCYTOPENIC PURPURA}

\section{To the Editor:}

We report the case of a 3 year-old girl with Guillain-Barré syndrome and idiopathic thrombocytopenic purpura.

She was admitted to the Children's Hospital of Tunis because she suddenly developed, some days after an upper respiratory tract infection, bilateral and symmetric weakness of the lower limbs. During the first week, she suffered from abdominal muscle weakness with moderate respiratory insufficiency and became unable to walk or stand without support. The clinical evaluation revealed a hypotonic paraplegia with total absence of the deep tendon reflexes. The CSF contained $60 \mathrm{mg} \%$ of protein with normal cell count. After ten days of evolution, she was noted to have fever and extensive purpuric spots. The full blood cell analysis and the bone marrow film confirmed a diagnosis of idiopathic thrombocytopenic purpura.

This observation suggests the possibility that the same antibody may be directed against platelets and one of the main proteins of the peripheral nerves, and could be responsible for the two diseases. Platelet antibody assays could be performed in all cases of Guillain-Barré and idiopathic thrombopenic purpura. Immunological studies of peripheral nerve, using platelet antibody may be useful to verify whether this antibody is directed against the nerve.

\section{Faouzia Khaldi* Abdelmajid Larnaout** Najoua Miladi** Béchir Bennaceur* *Children Hospital of Tunis Jabbari, Tunis **National Institute of Neurology La Rabta, Tunis}

1. Antoine JC, Micheld D, Le Petit JC, et al. Sous populations lymphocytaires du sang et du liquide céphalorachidien dans les polyradiculonévrites aigues. Rev Neurol 1985; 141: 740-743.

2. Cook SD, Dowling PC. The role of auto-antibody and immune complexes in the pathogenesis of Guillain-Barré syndrome. Ann Neurol 1981; 9: 70-80.

\section{HTLV-1 ASSOCIATED MYELOPATHY IN CHILE}

To the Editor:

Power et al (Can J Neurol Sci 1989; 16: 330-335), described six cases of HTLV-1 associated myelopathy in Canada. One of the patients is a Chilean woman and they claimed that Tropical Spastic Paraparesis (TSP) has not yet been described in Chile. In 1988 we reported that HTLV-1 may be associated with myelopathy in Chile. ${ }^{1}$ Also the clinical and pathological picture of progressive spastic paraparesis (PSP) has been described.2-5 Up to now we have collected 52 patients with PSP. Twenty-three patients (44.2\%) had IgG antibodies against this virus in serum and CSF using ELISA and Western inmunoblot.

In Chile this entity affects whites, women more often
(78.3\%), who are middle-aged (mean 45.8 years), with a history of surgical interventions $(69.6 \%)$ and blood transfusion (34.8\%). The basic clinical characteristics were a slowly progressive spastic paraparesis, with an asymmetric onset and minimal sensory complaints in some cases. The duration of the disease is at present an average of 7.48 years (range: 1 to 22 years). The main laboratory findings have been a mononuclear pleocytosis in CSF in $34.8 \%$ of patients, an abnormal increase of IgG index in $88.2 \%$, and abnormal somatosensory evoked potential in $89.5 \%$ with a delayed latency and very low amplitude. Also, four patients presented thinning of the dorsal spinal cord on magnetic resonance imaging and/or myelography. Twenty-three relatives out of 13 positive cases were screened for antibodies against HTLV-1 in serum (ELISA and Western Blot). Three were positive.

Recently, Vasquez et al found a seropositivity of $1.67 \%$ in 954 blood donors in Hospital del Salvador, Santiago, (unpublished data, VI Congreso Chileno de Infectologia, Octobre, 1989). These findings support an endemic prevalence of HTLV-1 in Chile, a non-tropical region, thus widening its geographical distribution in the world.

Luis Cartier Fernando Araya Jose L. Castillo Renato Verdugo Department of Neurological Science Faculty of Medicine, Universidad de Chile Santiago de Chile

I. Cartier L, Araya F, Verdugo R, et al. Paraparesia espástica progresiva asociada a HTLV-I en Chile. Rev Chil Neuropsiquiat 1988; 26: R3, 20.

2. Cartier L, Araya F, Verdugo R. Progressive spastic paraparesis in Chile. In: Román G, Vernant J, Osame M, eds. "HTLV-I and the Nervous System". Alan R Liss Inc N. York 1989.

3. Cartier L, Mora C, Araya F, et al. HTLV-I Positive spastic paraparesis in a temperate zone. Lancet 1989; 11: 556-557.

4. Cartier L. Análisis histopatologico de tres casos Chilenos de paraparesia espástica esporádica progresiva del adulto. In: Zaninovic V, ed. "Retrovirus humanos". Fariva Editores, Cali. Colombia, 1989.

5. Mora C, Cartier L, Araya F, et al. Tropical spastic paraparesis: new clinical criteria. Neurology 1989; 39 (Suppl): (Abst.) N: 11: 286.

\section{PREOPERATIVE HYPERTENSION DOES PREDICT POST-CAROTID ENDARTERECTOMY HYPERTEN- SION}

\section{To the Editor:}

We read with interest the recent case report by Drs. Shuaib, Hunter and Anderson describing a patient who experienced multiple intracranial hemorrhages following carotid endarterectomy (CEA). ${ }^{1}$ These authors report that post-CEA hypertension may be a risk factor for post-CEA hemorrhage. They also suggest that post-CEA hypertension cannot be predicted since it has no relationship to preoperative blood pressure. We, however, believe that the preponderance of current evidence supports the 
premise that preoperative hypertension is a useful predictor of post-CEA hypertension.

The 1970 retrospective study of 27 patients quoted by the authors, found no correlation between mean preoperative blood pressure (BP) and the development of post-operative hypertension. ${ }^{2}$ Similarly, Bove et al in a prospective study of 100 CEAs, did not find a correlation between mean preoperative BP and post-operative hypertension. ${ }^{3}$ Both these studies defined postoperative hypertension as a rise in systolic BP of greater than $15 \mathrm{mmHg}^{2}$ or $40 \mathrm{mmHg}^{3}$ above preoperative levels. This definition, therefore, would overlook patients who were hypertensive preoperatively and who remained hypertensive postoperatively but did not develop a further rise in BP.

In contrast, several more recent studies have demonstrated a strong correlation between preoperative hypertension and the development of post-CEA hypertension. 4-8 Towne and Bernhard, retrospectively reviewed $253 \mathrm{CEAs}$ and found that $79.6 \%$ of the patients who developed severe post-operative hypertension (defined as systolic blood pressure (SBP) greater than $200 \mathrm{mmHg}$ ) were hypertensive preoperatively. ${ }^{4}$ Of these patients, $16.3 \%$ had controlled preoperative hypertension (SBP $<150 \mathrm{mmHg}$ on medications) and $63.2 \%$ had uncontrolled preoperative hypertension (SBP $>150 \mathrm{mmHG}$ with or without medications). Similarly, in a retrospective study of 166 CEAs, Asiddao et al reported that severe post-operative hypertension (BP > 200/110 $\mathrm{mmHg}$ ) occurred more frequently in patients with poorly controlled preoperative hypertension (BP $>170 / 95 \mathrm{mmHg}$ with or without medications) compared to those with controlled hypertension or normal blood pressure (52\%, $35 \%$ and $17 \%$ respectively). ${ }^{5}$ Overall, $78 \%$ of the patients in this study who developed severe post-operative hypertension had preoperative hypertension. Similar results were found in uncontrolled hypertensives in the retrospective study performed by Corson et al. 6

Skudlarick and Mooring prospectively studies 41 patients undergoing CEA. ${ }^{7}$ All hypertensive patients in this series were controlled on medications preoperatively and post-operative systolic BP was pharmacologically maintained between $100-150 \mathrm{mmHg}$. These authors found that $73 \%$ of the patients who required post-operative intervention for hypertension (SBP $>150 \mathrm{mmHg}$ ) were controlled hypertensives preoperatively. Similarly, Cafferata et al prospectively studied postoperative blood pressure control in 90 CEA procedures using a carotid nerve-sparing technique. ${ }^{8}$ Although the incidence of post-CEA hypertension was low in this series $(11 \%)$, these authors also found that patients with uncontrolled preoperative hypertension (BP $<140 / 90$ with or without medications) were more likely to develop post-operative hypertension compared to controlled hypertensives and normotensives $(24 \%, 14 \%$ and $5 \%$ respectively).

The statement by Shuaib et al suggesting that the development of post-CEA hypertension cannot be predicted on the basis of preoperative BP is, therefore, misleading. ${ }^{1}$ This statement implies that there is not benefit associated with achieving preoperative blood pressure control. We believe that the bulk of available evidence supports the premise that patients with preoperative hypertension, particularly those with poorly or uncontrolled hypertension, are at substantially higher risk of developing postCEA hypertension. Since patients who develop post-CEA hypertension are at higher risk for developing post-operative neurological complications adequate preoperative control of blood pressure is desirable. $1-5$

\section{Adrian W. Gelb \\ lan A. Herrick \\ Department of Anaesthesia \\ University Hospital \\ London, Canada}

I. Shuaib A, Hunter M, Anderson MA. Multiple intracranial hemorrhages after carotic endarterectomy. Can J Neurol Sci 1989; 16: 345-347.

2. Lehv M, Salzman EW, Silen W. Hypertension complicating carotid endarterectomy. Stroke 1970; 1: 307-313.

3. Bove EL, Fry WJ, Gross WS, et al. Hypotension and hypertension as consequences of barareceptor dysfunction following carotid endarterectomy. Surgery 1979; 85: 633-637.

4. Towne JB, Bernhard VM. The relationship of postoperative hypertension to complications following carotid endarterectomy. Surgery 1980; 88: 575-580.

5. Asiddao CB, Donegan JH, Whitesell RC, et al. Factors associated with perioperative complications during carotid endarterectomy. Anesth Analg 1982; 61: 631-637.

6. Corson JD, Chang BB, Leopold PW, et al. Perioperative hypertension in patients undergoing carotic endarterectomy: shorter duration under regional block anesthesia. Circulation 1986; 74 (Suppl 1): 1-4.

7. Skudlarick JL, Mooring SL. Systolic hypertension and complications of carotid endarterectomy. South Med J 1982; 75: 15631565.

8. Cafferata HT, Merchant RF, DePalma RG. Avoidance of post carotid endarterectomy hypertension. Ann Surg 1982; 196: 465472.

\section{REPLY FROM AUTHOR}

It is a pleasure to respond to the letter of Drs Gelb and Herrick. They provide convincing evidence from three retrospective and two prospective studies that post-operative hypertension after carotid endarterectomy (CEA) can be predicted if patients have pre-operative hypertension. At the time of writing of our case report, we had conducted a literature search of articles on post-CEA "hemorrhage" and thus did not get access to the important literature on post-CEA "hypertension". We had based the statement regarding the unpredictability of preoperative hypertension as a predictor of post-CEA hypertension on the study of Lehv et al. As outlined in the letter of Gelb and Herrick, this study had shown no relationship between the mean pre-operative blood pressure and the development of post-CEA hypertension.

The clinical evidence summarized by Drs Gelb and Herrick shows that, in fact, a close relationship does exist between preoperative blood pressure and the development of post-CEA hypertension. We believe this information may have relevance to the development of post-CEA cerebral hemorrhage. in our case report, we postulated that the presence of long standing (and often poorly controlled) hypertension, leading to the development of small micro-aneurysms in the brain, may be a risk factor for the development of post-CEA cerebral hemorrhage. The sudden increase in blood pressure in the immediate postCEA period may then lead to rupture of the microaneurysms and thus cerebral hemorrhage. Our review of the literature, at the time of writing, showed no reports where the presence of 